\title{
Cognitive Impairment Associated with Schizophrenia: a Review of the Humanistic Burden
}

\author{
Helen Kitchen · Diana Rofail · Louise Heron · Pat Sacco
}

To view enhanced content go to www.advancesintherapy.com Received: October 27, 2011 / Published online: February 10, 2012

(C) The Author(s) 2012. This article is published with open access at Springerlink.com

\section{ABSTRACT}

Introduction: Nearly every individual with schizophrenia is affected by cognitive decline. The aim of this literature review was to: (a) describe the humanistic burden of cognitive impairment associated with schizophrenia (CIAS); (b) develop a conceptual model that depicts the signs and symptoms of CIAS along with key concepts important to patients; and (c) consider the adequacy of potential patientreported outcome (PRO) instruments for assessing future treatments.

H. Kitchen $(\bowtie)$

Adelphi Values, Adelphi Mill, Bollington, Cheshire,

SK10 5JB, UK. Email: helen.kitchen@adelphivalues.com

D. Rofail · L. Heron

Adelphi Values, Bollington, Cheshire, UK

P. Sacco

Novartis Pharmaceuticals Corporation, East Hanover, NJ, USA

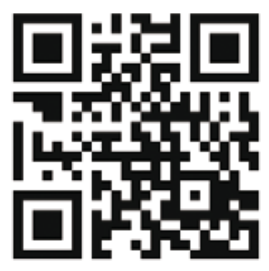

Enhanced content for Advances in Therapy articles is available on the journal web site: www.advancesintherapy.com
Methods: The following electronic databases were searched for articles published between January 1999 and November 2009 related to CIAS and PROs, or cost of illness: Medline; Embase; PsycINFO; the Health Economic Evaluation Database; and the National Health Service Economic Evaluation Database and Health Technology Assessment databases at the Centre for Reviews and Dissemination, University of York.

Results: The literature search revealed 3950 abstracts, of which 101 articles were reviewed in detail. Cognitive functions affected include memory, attention/concentration, problem solving, learning, executive function, processing speed, and social cognition. Cognitive impairment impacts the ability of individuals to carry out activities of daily living, work productively, function socially, and adhere to treatment. These effects have economic ramifications through increased direct and indirect costs associated with the treatment of schizophrenia. The literature revealed 39 PRO instruments that have been used to assess functioning. However, no single instrument captures all key concepts of importance to patients with schizophrenia.

Conclusion: The significant burden from CIAS for patients and society has implications for 
designing future treatments and health strategies to improve functional outcomes.

Keywords: burden; cognitive impairment associated with schizophrenia; conceptual model; cost; humanistic; patient reported outcome; schizophrenia

\section{INTRODUCTION}

Schizophrenia is a serious mental disorder affecting approximately $1 \%$ of the US population [1] and 24 million people worldwide [2]. It is characterized by the occurrence of positive symptoms [3], such as hallucinations or delusions [4], and negative symptoms [3], such as avolition [5], affective flattening, and social withdrawal [6]. Though schizophrenia affects a relatively small proportion of the population, it incurs substantial individual, societal, and healthcare costs $[7,8]$.

Cognitive deficits are not yet included in the diagnostic criteria for schizophrenia, but are considered a core feature of schizophrenia symptomatology $[9,10]$. While neuropsychological impairment may not be present in all patients with schizophrenia [11], almost all patients with schizophrenia display some cognitive impairment in comparison with healthy controls [12]. Cognitive impairments are often fully developed when patients present with a first episode of illness $[13,14]$. Impairment occurs in most aspects of cognition, including attention, verbal learning and memory, secondary memory, working memory, and executive functions $[10,15,16]$. Indeed, cognitive impairments can reach two standard deviations below the normal mean [10]. These impairments are not the result of positive or negative symptoms, or accounted for by motivational deficits [17]. Furthermore, in most cases, cognitive impairments do not worsen or improve with illness progression [17].

While cognitive deficits appear to be strong predictors of functional outcome [9], currently there is no US Food and Drug Administration (FDA) or European Medicines Agency (EMA) approved treatment targeting cognitive impairment associated with schizophrenia (CIAS). Treatments available for schizophrenia include typical and atypical antipsychotics, which predominantly target the positive symptoms of schizophrenia [18]. Despite the availability of antipsychotic medications, patients with schizophrenia are often unsuccessful in re-entering the community [19] and treatments do not appear to improve cognitive function beyond practice effects [20,21]. Therefore, treatments for cognitive impairment have been identified as an unmet need [22].

In an effort to improve functional outcomes for patients with schizophrenia, pharmacological research has focused on the improvement of cognitive deficits [23]. Improving patients' treatment experience is also a focus of the US National Institute of Mental Health (NIMH). The NIMH established the Measurement and Treatment Response to Improve Cognition in Schizophrenia (MATRICS), an academic/industry partnership.

A primary goal of the MATRICS was to decide on appropriate methods for evaluating new drugs [19]. The MATRICS Consensus Cognitive Battery (MCCB) was designed to provide new conventions for evaluating cognitive deficits in schizophrenia and aid in measuring treatment-related changes [24]. Seven independent cognitive domains were included in the MCCB: speed of processing, attention/ vigilance, working memory, verbal learning and memory, visual learning and memory, reasoning and problem solving (executive functioning), 
and social cognition [19]. The MCCB consists of 10 cognitive tests designed to assess each domain [24].

Clinician-reported outcomes and performance on cognitive tasks are important in assessing patient prognosis and treatment efficacy. However, the patient perspective can also provide valuable insights $[25,26]$ and may provide a link between cognitive performance and the patient's actual level of real-world functioning [27]. To date, patient-reported outcomes (PRO) instruments have not been evaluated for assessing treatments for CIAS. To assess PRO instruments and, specifically, comprehensiveness of the concepts measured, it is important to understand the humanistic burden of CIAS, which has not yet been summarized.

Specifically, there is no conceptual model of the burden of CIAS on patients' lives. Conceptual models summarize the key concepts related to an illness or condition that could be measured with a PRO instrument. A conceptual model provides a visual representation of key concepts important to patients and they relate to each other [28]. The model compartmentalizes potential causes, consequences, and signs and symptoms of the disease. The purpose of a conceptual model is to provide a basis for assessing PRO questionnaires. For example, to adequately measure the impact of CIAS, a PRO questionnaire should capture all concepts of importance to patients.

Furthermore, various PRO questionnaires have been used in studies with patients with schizophrenia (eg, the Social Functioning Scale [SFS]) [29]. However, their suitability have not been thoroughly considered in light of the nature of schizophrenia guidelines, such as the MATRICS initiative $[19,30]$, or the FDApublished PRO guidelines [31].

This literature review explores studies in schizophrenia related to cognitive impairment,
PRO, or cost with the view to: (a) describe the humanistic burden of CIAS; (b) develop a conceptual model of CIAS to identify key concepts important to patients; and (c) consider the adequacy of PRO instruments for future studies.

\section{METHODS}

\section{Electronic Database Search}

Using guidelines defined by the University of York National Health Service (NHS) Centre for Reviews \& Dissemination (CRD) [32], a search strategy was developed. Three electronic databases (Medline, PsycINFO, and Embase) were searched for articles published between January 1999 and November 2009. The terms used are provided in Table 1.

\section{Economic Database Searches}

Using the cost terms (Table 1), the following databases were searched: Health Economic Evaluation Database (HEED); and the NHS Economic Evaluation Database (NHS-EED) and Health Technology Assessment (HTA) databases at the CRD, University of York.

\section{National Institute of Mental Health (US) Review}

Key publications relating to the NIMH MATRICS initiative were also reviewed for information related to impaired cognition in schizophrenia and recommendations for measurement of cognitive function $[19,22,24,27,30,33]$.

\section{Inclusion and Exclusion Criteria}

All titles and abstracts were screened for inclusion in the study by two researchers. 
Table 1. Database search terms.

\begin{tabular}{|c|c|c|}
\hline Clinical and medication terms & $\begin{array}{l}\text { Schizophrenia AND antipsychotic OR neuroleptics OR } \\
\text { acetylcholinesterase inhibitors OR modafinil OR memantine OR } \\
\text { nicotinic acetylcholine receptor agonist }\end{array}$ & AND \\
\hline Cognition terms & $\begin{array}{l}\text { Cognitive improvement OR cognitive enhancement OR } \\
\text { cognitive function OR cognitive deficits OR neurocognitive deficits OR } \\
\text { executive function OR mental status OR cognitive capacity OR } \\
\text { cognitive assessment OR cognitive performance OR cognition OR } \\
\text { memory OR confusion OR concentration }\end{array}$ & AND \\
\hline PRO term & $\begin{array}{l}\text { Health-related quality of life OR quality of life OR patient burden OR } \\
\text { patient impact OR self-care OR relationships OR family impact OR } \\
\text { functional status OR functional capacity OR functional performance OR } \\
\text { functional impairment OR psychosocial OR social functioning OR } \\
\text { emotions* OR symptom* OR work OR activities of daily living OR } \\
\text { patient experience OR subjective experience OR qualitative }\end{array}$ & OR \\
\hline Cost term & $\begin{array}{l}\text { Cost* OR cost of illness OR economic burden OR financial burden OR } \\
\text { economic impact OR spending on treatments OR resource use OR } \\
\text { hospitalization OR unmet need OR consumption of healthcare resources OR } \\
\text { productivity loss OR resource management OR absenteeism OR } \\
\text { expenditure OR emergency services OR outpatient services OR disability }\end{array}$ & \\
\hline
\end{tabular}

$\mathrm{PRO}=$ patient-reported outcome.

*Search for truncated term.

To be included, abstracts had to contain a clinical and medication term, a cognition term, and at least one of the PRO or cost terms. Journal articles were limited to English language and human subjects. The selected studies contained keywords in the title or abstract. Studies were excluded only if the reviewers agreed that they did not fulfill the criteria.

\section{Ranking Process}

The selected studies were ranked according to whether relevant terms in the title/abstract were: (a) the focus of the article; (b) provided as secondary or exploratory to the focus of the article; or (c) mentioned in the background or the discussion. Only articles ranked 1 were included for further consideration.

\section{Data Extraction}

Data extraction tables were developed to extract information accurately on relevant features and results of the selected studies. The key components of the data extraction tables were general information relating to the authors, publication date, country of study, and reference, as well as specific information relating to the aims of the study, patient population, sample size, study design, treatments, cognitive impairment and PRO measurements, main PRO and cognitive impairment results, and key concepts to consider.

\section{Development of Conceptual Model}

Key concepts were identified from the published literature, with a particular focus on studies 
reporting qualitative data from the patient perspective. Relationships between concepts were identified from reported results specifically relating to cognitive impairment.

\section{PRO Instrument Evaluation Criteria}

The PRO instruments identified were reviewed according to criteria outlined by the US FDA Guidance for Industry [31]:

- Conceptual framework: Documentation of a diagram that defines concepts measured by the instrument, relationships between items, domain (sub-concepts) and concept measured, and scores produced by a PRO instrument.

- Content validity: Extent to which the instrument measures the concepts of interest (ie, inclusion of items and domains that are appropriate and comprehensive relative to its intended measurement concept, population, and use).
- Psychometric properties: Elements that contribute to the statistical adequacy of an instrument, where relevant, in terms of reliability, construct validity, and ability to detect change.

- Characteristics: Number of items, mode of administration, response options, scoring, and recall period.

Instruments that had been used in $\geq 3$ studies were considered for further review, using FDA PRO guidance.

\section{RESULTS}

\section{Study Selection}

Fig. 1 shows the number of abstracts reviewed and the article selection process. The literature search revealed 3950 abstracts, of which 101 articles were reviewed in detail.

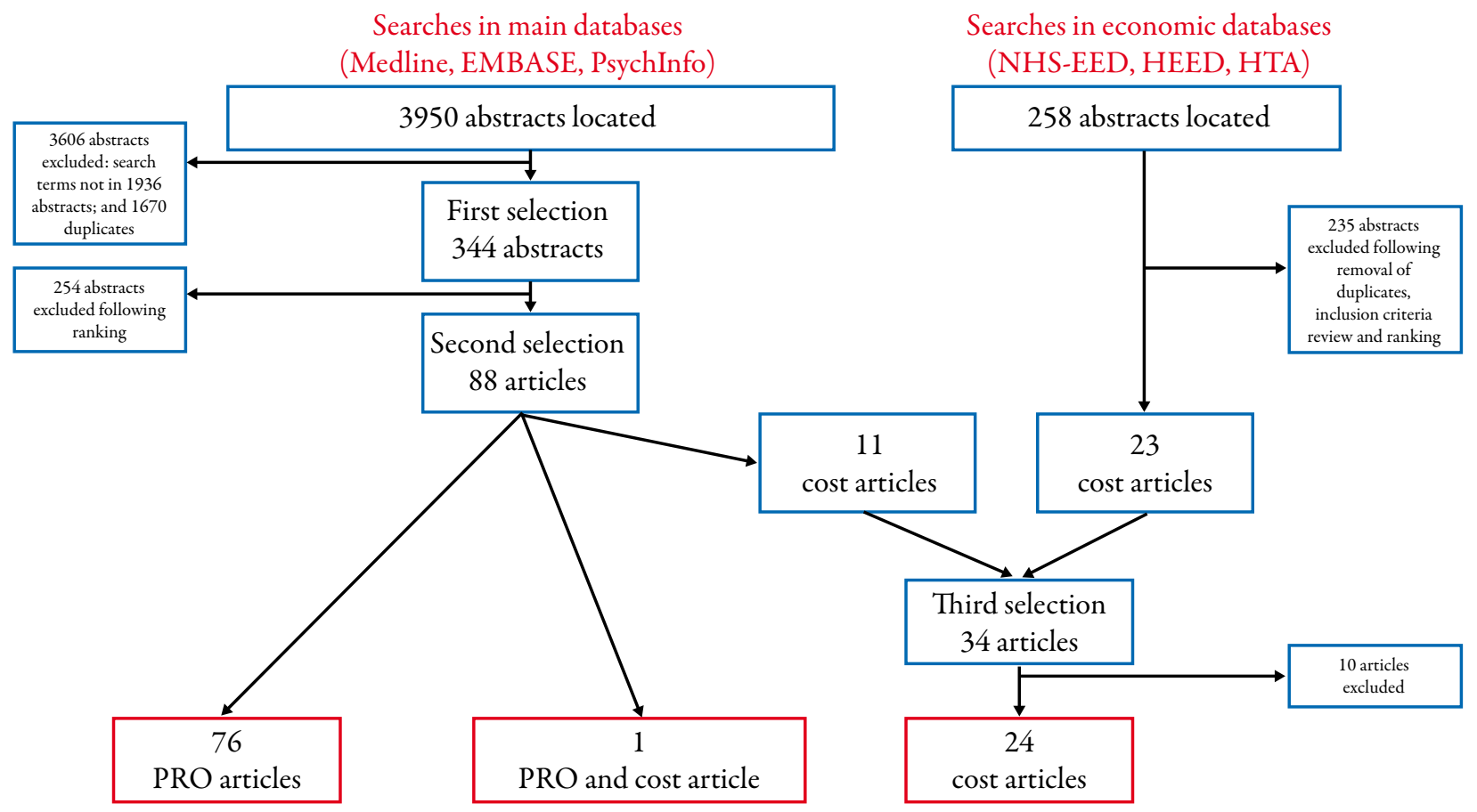

Fig. 1. Article selection process. HEED=Health Economic Evaluation Database; HTA=Health Technology Assessment; NHS-EED=National Health Service Economic Evaluation Database; PRO=patient-reported outcome. 


\section{Cognitive Impairment Associated with Schizophrenia}

Cognitive functions appear to be impaired in patients with schizophrenia (Fig. 2). Some cognitive dysfunctions are present during childhood and early adolescence; thus, predating the onset of psychosis [15]. Furthermore, treatment with conventional antipsychotic medication may exacerbate impaired cognitive functioning $[34,35]$.

\section{Effects of Treatment on Cognitive}

\section{Impairment Associated with Schizophrenia}

Although evidence suggests that cognitive deficits are specific to schizophrenia itself and not a side effect of neuroleptic medication $[10,15]$, cognitive functions may decline further as a side effect of typical antipsychotics $[6,35]$. These appear to have detrimental impact on cognition and functional outcomes [36]. While a lower dosage of some typical antipsychotics may reduce cognitive impairments and some atypical antipsychotic medications do not appear to worsen cognitive impairment, a significant improvement is not apparent. In addition, anticholinergic drugs, used as adjunctive treatment for extrapyramidal side effects, may also affect cognition, particularly memory [37]. Side effects can impact the patient's attitude to medication and may be a cause of nonadherence to the medication regimen [38].

\section{Humanistic Burden of Cognitive Impairment Associated with Schizophrenia}

Cognitive impairment appears to have a significant impact upon patients' lives; affecting activities of daily living [9], independent living $[6,18]$, social functioning $[16,39,40]$, relationships [41], and the ability to work $[36,42]$ (Fig. 3).

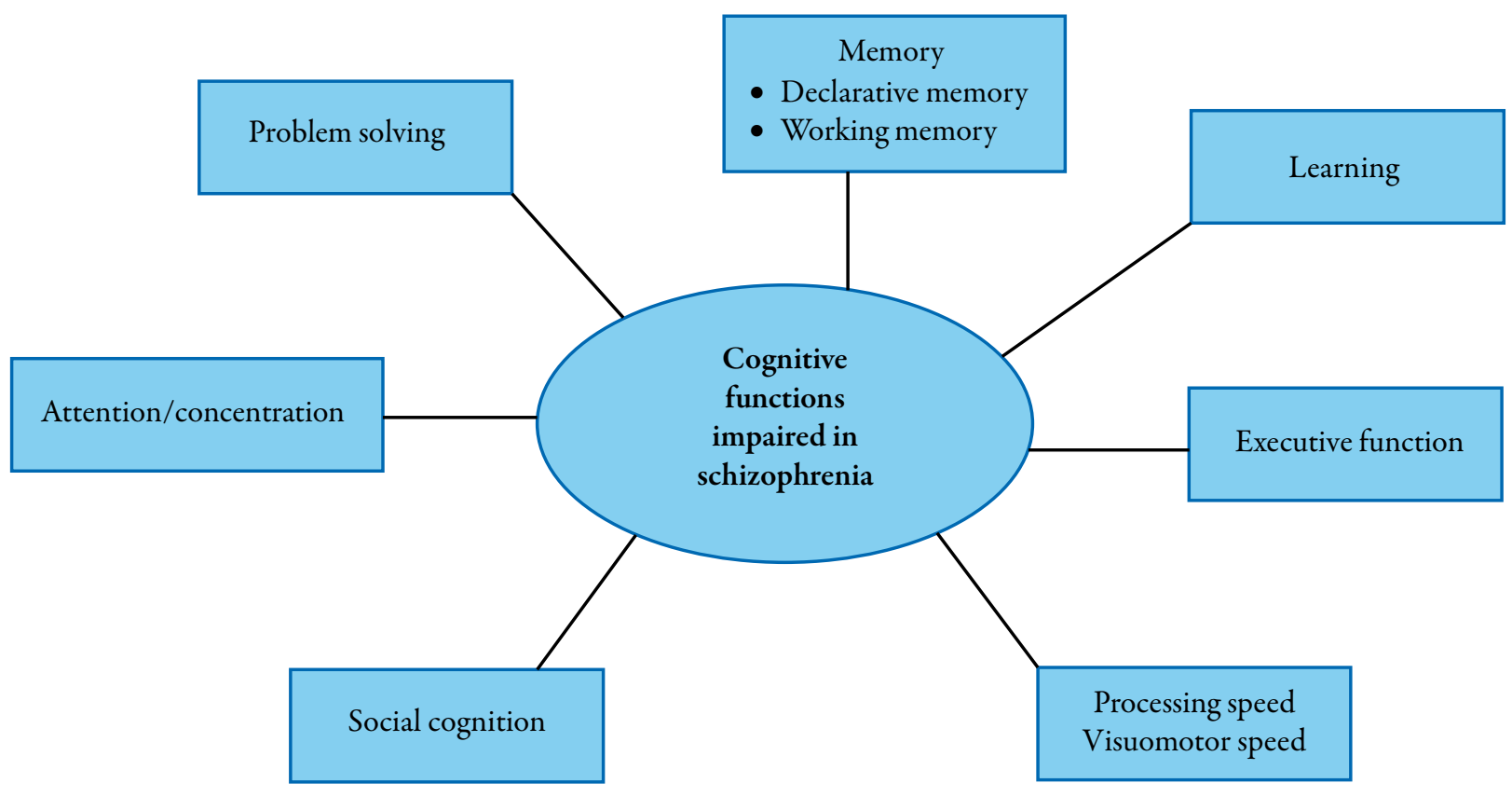

Fig. 2. Cognitive functions impaired in patients with schizophrenia. 

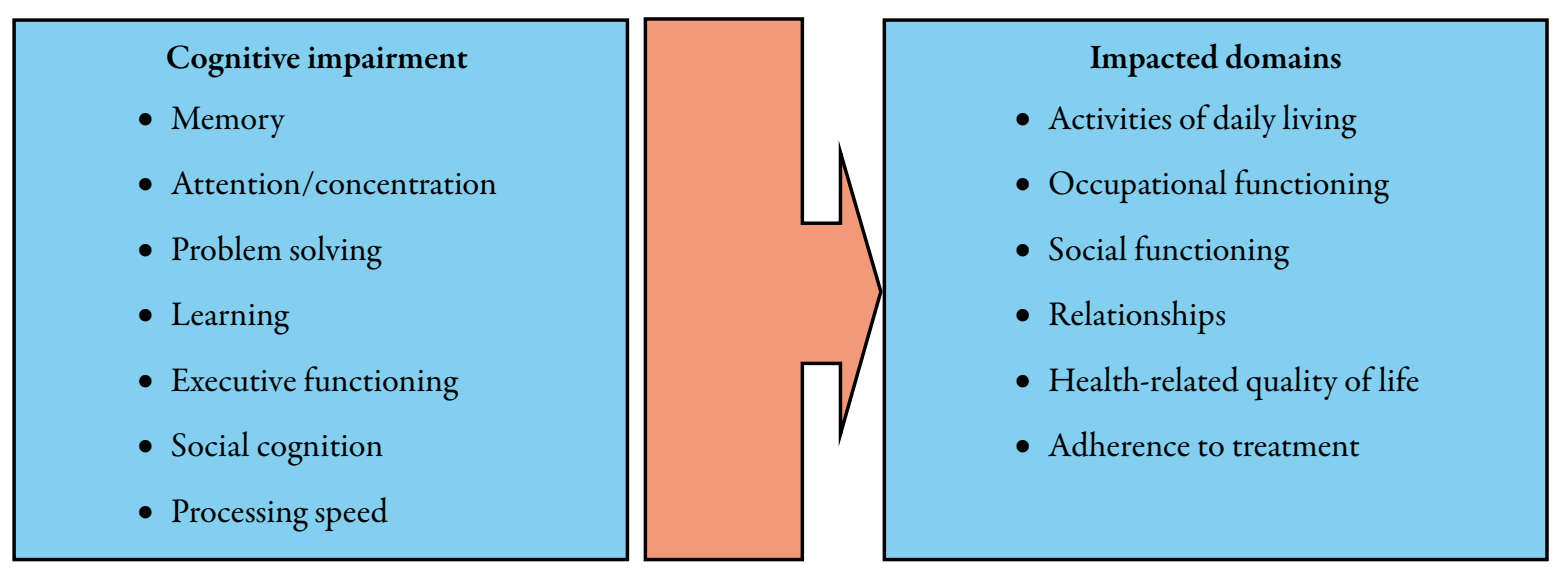

Fig. 3. Impact of CIAS on patients with schizophrenia. CIAS=cognitive impairment associated with schizophrenia.

\section{Conceptual Model}

Based on the literature, Fig. 4 [43-67] illustrates a conceptual model of CIAS. Positive, negative, and affective symptoms, as well as impaired cognitive functions and side effects of treatment contribute to the burden of schizophrenia. In addition, the impact may be influenced by psychosocial factors, such as social support and a relationship with healthcare professionals.

\section{Using PRO Instruments to Measure the Impact of Cognitive Impairment Associated with Schizophrenia on Patients}

From the articles reviewed, 39 different PRO instruments were identified. These included measures of health-related quality of life (HRQoL) $(n=12)$, symptoms $(n=8)$, functioning $(n=7)$, subjective experience with treatment $(n=4)$, activities of daily living $(n=2)$, side effects $(n=2)$, insight into schizophrenia $(n=1)$, and sleep $(n=1)$. The other two instruments measured aspects of personality or body image.

Table 2 indicates whether instruments were developed for use in patients with schizophrenia or for use in a range of disease areas and/or in general populations.

\section{Economic Burden of Cognitive Impairment Associated with Schizophrenia}

No publications were identified that focused on the economic burden of CIAS. The total economic burden of schizophrenia was reported to be up US\$62 million; however, this varied considerably between countries (due to varying patient populations) and different methods of cost data collection and estimation [7,8,68-70]. The contributing factors to the economic burden of schizophrenia include direct costs (inpatient hospitalization, outpatient hospital care, drug costs, residential/social/day care, and community medical services) and indirect costs (carer burden, lost productivity, premature death, and criminal justice system). Drug costs, for either typical or atypical antipsychotics, represent less than a quarter of the direct costs of schizophrenia $[8,70-76]$. Inpatient costs account for the majority of the direct costs [71] of schizophrenia, driven largely by relapse and re-hospitalization of patients due to noncompliance with medication, leading to more frequent and severe episodes of psychosis [72,77]. Indirect costs, and in particular lost productivity costs, represent the majority of the total costs of 


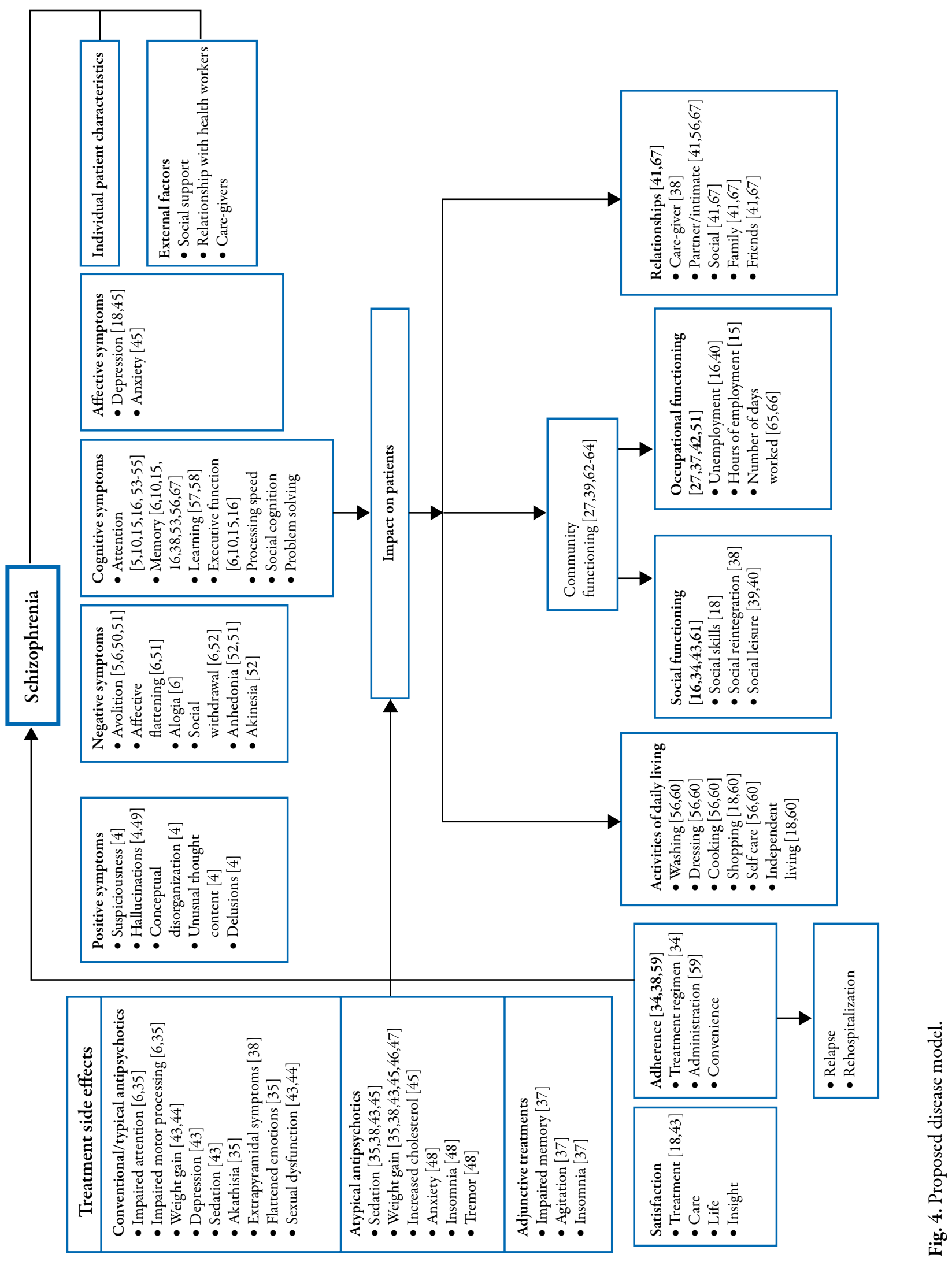




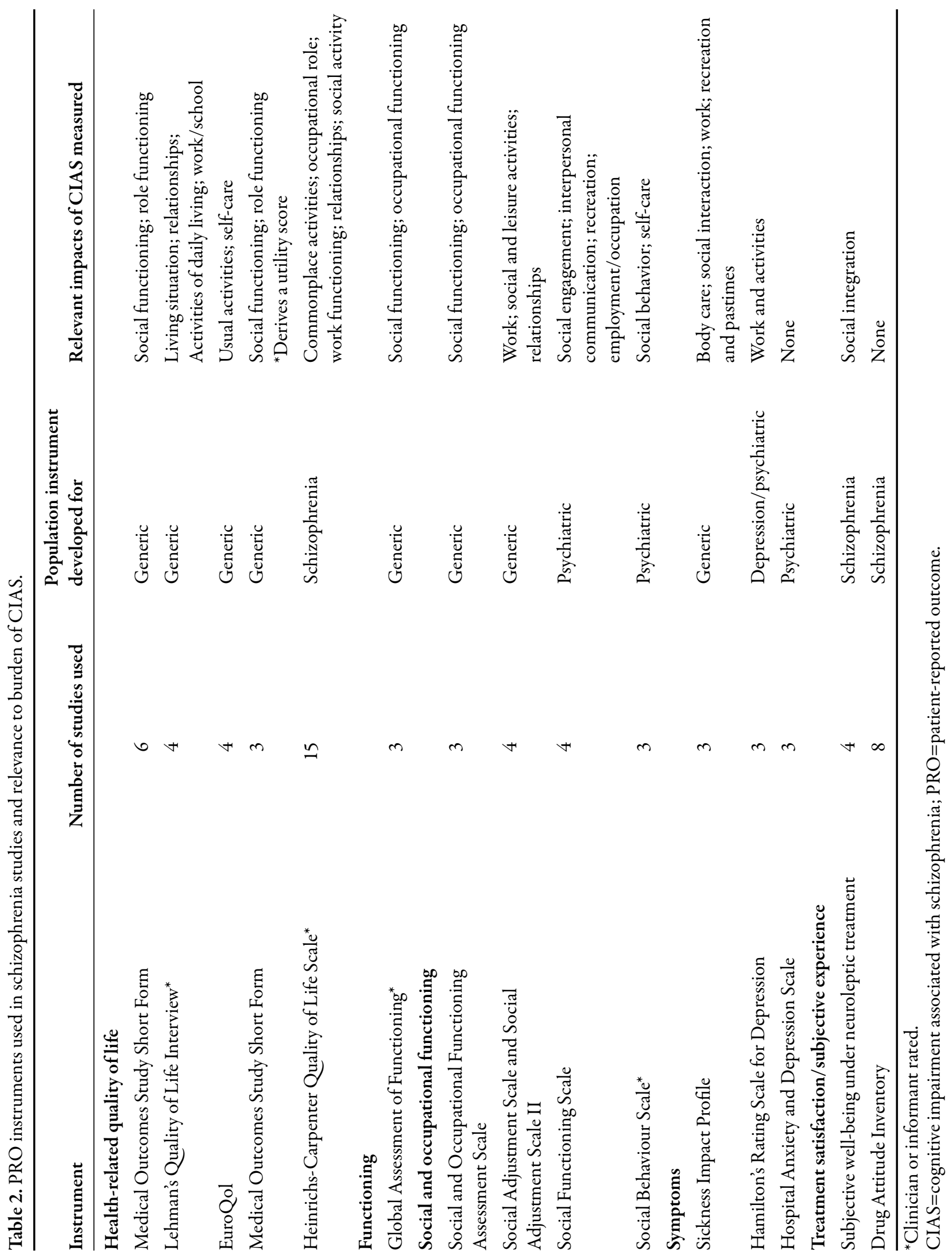


schizophrenia $[7,8,69,70,74,78]$. Typically, only $20 \%$ of patients with schizophrenia find paid employment and $80 \%$ are unable to return to work following the first episode of psychosis; even when paid employment is achieved, job tenure is a frequent problem for patients, who appear to fare worse in the workforce than patients with other mental disorders $[78,79]$. From the studies identified, it is not possible to determine which of these costs are directly attributable to cognitive impairment; however, studies have reported a link between cognitive functioning and employment in schizophrenia $[42,79,80]$.

\section{DISCUSSION}

This review explored the impact of cognitive impairment on patients with schizophrenia, and presents preliminary findings. Additionally, a conceptual model was developed to illustrate the patient's experience of cognitive impairment with the aim of improving our understanding of the concepts that are important to patients relative to their disease. Cognitive dysfunction is apparent in emotional, social, educational, functional, and occupational areas of patients' everyday lives. Cognitive impairment is also a barrier to medication adherence (typically due to working and long-term memory difficulties) [59]. This can be problematic for the individual, worsening positive and negative symptomatology [34], and may lead to increased costs. Adequate diagnosis, management, and treatment of CIAS are required to improve the patient's experience, and minimize the burden of illness for patients and society.

Schizophrenia is a costly psychiatric disorder to manage; the annual cost of an average patient with schizophrenia is reported to be significantly higher than other mental health conditions [8]. This review highlighted a paucity of evidence focusing on the economic burden of CIAS specifically. Cognitive functioning, more than positive or negative symptoms, is the major determinant of functional and employmentrelated outcomes in schizophrenia $[42,79,80]$. As cognition is associated with employment outcomes $[42,79,80]$ (and therefore loss of productivity), further research quantifying the direct and indirect costs of CIAS would be of great value.

New pharmacologic interventions are in development, and PRO instruments can be used to assess the impact of treatments on patient functioning in both clinical trials and clinical practice. Many studies rely on clinician assessment or experimental tasks to measure cognitive performance and patient functioning. However, there is a lack of research into the discrepancy between functional skills and what patients are actually able to do in the real world [9]. In addition, few clinical trials include a PRO as an endpoint, which could provide important insight about a patient's ability to function and overall HRQoL. Depending on the severity of cognitive impairment and the stage of episode, patients with schizophrenia are able to self-rate their affective state of well-being and level of functioning $[77,81]$. However, the individual may be less aware of the severity of their illness and its impact on their functioning and, therefore, as cognition and insight improve, there may be a paradoxical decline in perceived HRQoL [43].

A number of PRO instruments have been used in studies with patients with schizophrenia. No single instrument captures all key concepts of importance to patients with schizophrenia, and the appropriateness of a PRO instrument should be considered in light of its development history, face and content validity, psychometric properties, and purpose for use [31]. Many of the instruments used 
to assess patient functioning were developed in a general or nonschizophrenia patient population (eg, the Medical Outcomes Study Short Form [SF-36], Sickness Impact Profile [SIP], and Social Adjustment Scale [SAS] I and II). Consequently, concepts of importance may not have been adequately measured; this may affect the validity of results based upon these instruments. Furthermore, the schizophreniaspecific instruments and those developed for a psychiatric population (eg, Heinrichs-Carpenter Quality of Life Scale and Social Behavior Scale [SBS]) rely on a clinician rating. A clinician or informant rating does not provide a direct report of patient experience; potentially leading to a discrepancy between the patient experience and data provided.

It is important to recognize the limitations of this review. The findings are based on studies published in English over the last 10 years to capture only the most recent and up-to-date studies. The authors recognize that these inclusion criteria may have led to a bias in the results presented. There is a dearth of qualitative research with patients or caregivers that describe patients' experiences of CIAS in depth. The conceptual model presented in this paper should, therefore, be used as an exploratory framework for further research into the real-world functioning of patients with schizophrenia. Only by exploring and documenting patient experiences can adequate and appropriate measurement tools be developed.

This literature review suggests there is a lack of adequate PRO instruments for measuring the burden of CIAS. Further research to confirm the impact of cognitive impairment on patients with schizophrenia would be necessary in order to modify or develop appropriate, valid PRO measures to assess new treatments targeting CIAS.

\section{CONCLUSION}

This review provides evidence that CIAS results in a significant burden for patients, healthcare systems, and society. Cognitive function may fluctuate throughout the course of illness, possibly exacerbated by current drug treatments and other psychosocial factors. The overall burden incurred suggests the need for treatments that improve cognitive function while not interacting with existing treatments, and that have a favorable safety profile. Given the value of assessing patient functioning in clinical trials and clinical practice, it is important that appropriate, valid PRO instruments are developed or identified to assess treatments targeting CIAS.

\section{ACKNOWLEDGMENTS}

Diana Rofail and Pat Sacco designed the study. Diana Rofail provided strategic consulting to Novartis and was senior support during implementation and completion of the project. Diana Rofail now works for Roche Pharmaceuticals. Helen Kitchen and Louise Heron implemented the literature searches and analyzed the findings. All authors drafted and finalized the manuscript. Helen Kitchen is the guarantor for this article, and takes responsibility for the integrity of the work as a whole.

Novartis Pharmaceuticals has commissioned Adelphi Values to consult on patient-reported outcome and health economic strategies for their forthcoming studies. Pat Sacco is an employee of, and owns shares in, Novartis Pharmaceuticals. All other authors are employed by Adelphi Values, a health outcomes agency that consults with various pharmaceutical companies.

Open Access. This article is distributed under the terms of the Creative Commons Attribution Noncommercial License which 
permits any noncommercial use, distribution, and reproduction in any medium, provided the original author(s) and source are credited.

\section{REFERENCES}

1. Regier DA, Narrow WE, Rae DS, et al. The de facto US mental and addictive disorders service system. Epidemiologic catchment area prospective 1-year prevalence rates of disorders and services. Arch Gen Psychiatry. 1993;50:85-94.

2. WHO. Mental Health and Substance Abuse: Facts and Figures, Schizophrenia. Available at: http:// www.searo.who.int/en/section1174/section1199/ section1567_6744.htm. Accessed November 1, 2009.

3. American Psychiatric Association. Diagnostic and Statistical Manual of Mental Disorders. 4th edition. Washington DC: American Psychiatric Association; 2011.

4. Velligan DI, Prihoda TJ, Sui D, et al. The effectiveness of quetiapine versus conventional antipsychotics in improving cognitive and functional outcomes in standard treatment settings. J Clin Psychiatry. 2003;64:524-531.

5. Brebion G, Bressan RA, Amador X, Malaspina D, Gorman JM. Medications and verbal memory impairment in schizophrenia: the role of anticholinergic drugs. Psychol Med. 2004;34:369374.

6. Sharma T, Antonova L. Cognitive function in schizophrenia. Deficits, functional consequences, and future treatment. Psychiatr Clin North Am. 2003;26:25-40.

7. Meltzer HY. Outcome in schizophrenia: beyond symptom reduction. J Clin Psychiatry. 1999;60 (suppl. 3):3-7; discussion 8.

8. Wu EQ, Birnbaum HG, Shi L, et al. The economic burden of schizophrenia in the United States in 2002. J Clin Psychiatry. 2005;66:1122-1129.

9. Bowie C, Harvey P. Cognitive deficits and functional outcome in schizophrenia. Neuropsychiatr Dis Treat. 2006;2:531-536.

10. Elvevag B, Goldberg TE. Cognitive impairment in schizophrenia is the core of the disorder. Crit Rev Neurobiol. 2000;14:1-21.
11. Palmer BW, Heaton RK, Paulsen JS, et al. Is it possible to be schizophrenic yet neuropsychologically normal? Neuropsychology. 1997;11:437-446.

12. Keefe RS. Should cognitive impairment be included in the diagnostic criteria for schizophrenia? World Psychiatry. 2008;7:22-28.

13. Bilder RM, Goldman RS, Robinson D, et al. Neuropsychology of first-episode schizophrenia: initial characterization and clinical correlates. Am J Psychiatry. 2000;157:549-559.

14. Harvey PD, Meltzer H, Simpson GM, et al. Improvement in cognitive function following a switch to ziprasidone from conventional antipsychotics, olanzapine, or risperidone in outpatients with schizophrenia. Schizophr Res. 2004;66:101-113.

15. Merlotti E, Piegari G, Galderisi S. Cognitive impairment as a core feature of schizophrenia. Minerva Psichiatr. 2005;46:67-77.

16. Meltzer HY. Beyond control of acute exacerbation: enhancing affective and cognitive outcomes. CNS Spectr. 2003;8(suppl. 2):16-8, 22.

17. Harvey PD, Green MF, Keefe RS, Velligan DI. Cognitive functioning in schizophrenia: a consensus statement on its role in the definition and evaluation of effective treatments for the illness. J Clin Psychiatry. 2004;65:361-372.

18. Ginsberg D, Schooler N, Buckley P, Harvey P, Weiden P. Optimizing treatment of schizophrenia. CNS Spectr. 2005;10:1-3.

19. Green MF, Nuechterlein KH. The MATRICS initiative: developing a consensus cognitive battery for clinical trials. Schizophr Res. 2004;72:1-3.

20. Goldberg TE, Goldman RS, Burdick KE, et al. Cognitive improvement after treatment with second-generation antipsychotic medications in first-episode schizophrenia: is it a practice effect? Arch Gen Psychiatry. 2007;64:1115-1122.

21. Keefe RS, Bilder RM, Davis SM, et al. Neurocognitive effects of antipsychotic medications in patients with chronic schizophrenia in the CATIE Trial. Arch Gen Psychiatry. 2007;64:633-647.

22. Buchanan RW, Davis M, Goff D, et al. A summary of the FDA-NIMH-MATRICS workshop on clinical trial design for neurocognitive drugs for schizophrenia. Schizophr Bull. 2005;31:5-19. 
23. Green MF, Nuechterlein KH. Should schizophrenia be treated as a neurocognitive disorder? Schizophr Bull. 1999;25:309-319.

24. Nuechterlein $K$, Green $M$, Kern $R$, et al. The MATRICS consensus cognitive battery, part 1: test selection, reliability, and validity. Am J Psychiatry. 2008;165:203-213.

25. McCabe R, Saidi M, Priebe S. Patient-reported outcomes in schizophrenia. Br J Psychiatry. 2007;50:S21-S28.

26. Hunter R, Cameron R, Norrie J. Using patientreported outcomes in schizophrenia: the Scottish Schizophrenia Outcomes Study. Psychiatr Serv. 2009;60:240-245.

27. Green MF, Kern RS, Heaton RK. Longitudinal studies of cognition and functional outcome in schizophrenia: implications for MATRICS. Schizophr Res. 2004;72:41-51.

28. McGrath C, Rofail D, Gargon E, Abetz L. Using qualitative methods to inform the trade-off between content validity and consistency in utility assessment: the example of type 2 diabetes and Alzheimer's disease. Health Qual Life Outcomes. 2010;8:23.

29. Birchwood M, Smith J, Cochrane R, Wetton S, Copestake S. The Social Functioning Scale. The development and validation of a new scale of social adjustment for use in family intervention programmes with schizophrenic patients. $\mathrm{Br} \mathrm{J}$ Psychiatry. 1990;157:853-859.

30. Marder SR, Fenton W. Measurement and Treatment Research to Improve Cognition in Schizophrenia: NIMH MATRICS initiative to support the development of agents for improving cognition in schizophrenia. Schizophr Res. 2004;72:5-9.

31. US Department of Health and Human Services Food and Drug Administration Center for Drug Evaluation and Research (CDER), Center for Biologics Evaluation and Research (CBER), Center for Devices and Radiological Health (CDRH). Guidance for Industry. Patient-Reported Outcome Measures: Use in Medical Product Development to Support Labeling Claims. Health Qual Life Outcomes. 2006;4:79.

32. University of York. Centre for Reviews and Dissemination. Systematic reviews: CRD's guidance for undertaking reviews in health care [Internet]. York: University of York; 2009. 27-11-2009. Available at: http://www.york.ac.uk/inst/crd/index_ guidance.htm. Accessed November 20, 2009.
33. Green MF, Nuechterlein KH, Gold JM, et al. Approaching a consensus cognitive battery for clinical trials in schizophrenia: the NIMHMATRICS conference to select cognitive domains and test criteria. Biol Psychiatry. 2004;56:301-307.

34. Burton S. Symptom domains of schizophrenia: the role of atypical antipsychotic agents. J Psychopharmacol. 2006;20(suppl.):6-19.

35. Moncrieff J, Cohen D, Mason JP. The subjective experience of taking antipsychotic medication: A content analysis of Internet data. Acta Psychiatr Scand. 2009;120:102-111.

36. Sharma T. Atypical antipsychotics and cognition in schizophrenia. Arch Gen Psychiatry. 2002;59:571572 .

37. Sharma T. Impact on cognition of the use of antipsychotics. Curr Med Res Opin. 2002;18(suppl. 3):S13-S17.

38. Gorwood P. Meeting everyday challenges: antipsychotic therapy in the real world. Eur Neuropsychopharmacol. 2006;16(suppl. 3):S156-S162.

39. Harvey P, Patterson T, Potter L, Zhong K, Brecher M. Improvement in social competence with short-term atypical antipsychotic treatment: A randomized, double-blind comparison of quetiapine versus risperidone for social competence, social cognition, and neuropsychological functioning. Am J Psychiatry. 2006;163:1918-1925.

40. Wittorf A, Wiedemann G, Buchkremer G, Klingberg S. Prediction of community outcome in schizophrenia 1 year after discharge from inpatient treatment. Eur Arch Psychiatry Clin Neurosci. 2007;258:48-58.

41. Heinrichs R. Cognitive improvement in response to antipsychotic drugs: Neurocognitive effects of antipsychotic medications in patients with chronic schizophrenia in the CATIE trial. Arch Gen Psychiatry. 2007;64:631-632.

42. Hofer A, Baumgartner S, Bodner T, et al. Patient outcomes in schizophrenia II: the impact of cognition. Eur Psychiatry. 2005;20:395-402.

43. Chue P. The relationship between patient satisfaction and treatment outcomes in schizophrenia. J Psychopharmacol. 2006;20(suppl.):38-56.

44. Hofer A, Kemmler G, Eder U, et al. Quality of life in schizophrenia: the impact of psychopathology, attitude toward medication, and side effects. J Clin Psychiatry. 2004;65:932-939. 
45. Kasper S. Optimisation of long-term treatment in schizophrenia: treating the true spectrum of symptoms. Eur Neuropsychopharmacol. 2006;16 (suppl. 3):S135-S141. Epub: 2006.

46. Stratta P, Donda P, Rossi A, Rossi A. Executive function assessment of patients with schizophrenic disorder residual type in olanzapine treatment: an open study. Hum Psychopharmacol. 2005;20:401408.

47. Voruganti L, Cortese L, Owyeumi L, et al. Switching from conventional to novel antipsychotic drugs: results of a prospective naturalistic study. Schizophr Res. 2002;57:201-208.

48. Ciudad A, Olivares J, Bousono M, Gomez J, Alvarez E. Improvement in social functioning in outpatients with schizophrenia with prominent negative symptoms treated with olanzapine or risperidone in a 1 year randomized, open-label trial. Prog Neuropsychopharmacol Biol Psychiatry. 2006;30:1515-1522.

49. Bell M, Mishara A. Does negative symptom change relate to neurocognitive change in schizophrenia? Implications for targeted treatments. Schizophr Res. 2006;81:17-27.

50. O'Grada C, Dinan T. Executive function in schizophrenia: what impact do antipsychotics have? Hum Psychopharmacol. 2007;22:397-406.

51. Meltzer HY. Cognitive factors in schizophrenia: causes, impact, and treatment. CNS Spectr. 2004;9(suppl. 11):15-24.

52. Carpenter J. Clinical constructs and therapeutic discovery. Schizophr Res. 2004;72:69-73.

53. Delle CR, Salviati M, Fiorentini S, Biondi M. Addon mirtazapine enhances effects on cognition in schizophrenic patients under stabilized treatment with clozapine. Exp Clin Psychopharmacol. 2007; 15:563-568.

54. Gráda C, Barry S, McGlade N, et al. Does the ability to sustain attention underlie symptom severity in schizophrenia? Schizophr Res. 2009;107:319-323.

55. Harris JG, Minassian A, Perry W. Stability of attention deficits in schizophrenia. Schizophr Res. 2007;91:107-111.

56. Rosse RB, Deutsch SI. Adjuvant galantamine administration improves negative symptoms in a patient with treatment-refractory schizophrenia. Clin Neuropharmacol. 2002;25:272-275.
57. Matsui M, Sumiyoshi T, Arai H, Higuchi Y, Kurachi M. Cognitive functioning related to quality of life in schizophrenia. Prog Neuropsychopharmacol Biol Psychiatry. 2008;32:280-287.

58. Laes J, Sponheim S. Does cognition predict community function only in schizophrenia?: a study of schizophrenia patients, bipolar affective disorder patients, and community control subjects. Schizophr Res. 2006;84:121-131.

59. Bhanji NH, Chouinard G, Margolese HC. A review of compliance, depot intramuscular antipsychotics and the new long-acting injectable atypical antipsychotic risperidone in schizophrenia. Eur Neuropsychopharmacol. 2004;14:87-92.

60. Guaiana G, Tyson P, Roberts K, Mortimer A. Negative symptoms and not cognition predict social functioning among patients with schizophrenia. Schweiz Arch Neurol Psychiatr. 2007;158:25-31.

61. Weiss EM, Bilder RM, Fleischhacker WW. The effects of second-generation antipsychotics on cognitive functioning and psychosocial outcome in schizophrenia. Psychopharmacology (Berl). 2002;162:11-17.

62. Goff D. New insights into clinical response in schizophrenia: From dopamine Dsub 2 receptor occupancy to patients' quality of life. Am J Psychiatry. 2008;165:940-943.

63. Velligan DI, Miller AL. Cognitive dysfunction in schizophrenia and its importance to outcome: the place of atypical antipsychotics in treatment. J Clin Psychiatry. 1999;60(suppl. 23):25-28.

64. Harvey PD. Ziprasidone and cognition: the evolving story. J Clin Psychiatry. 2003;64:33-39.

65. Perlick DA, Rosenheck RA, Kaczynski R, Bingham $\mathrm{S}$, Collins J. Association of symptomatology and cognitive deficits to functional capacity in schizophrenia. Schizophr Res. 2008;99:192-199.

66. Mohamed S, Rosenheck R, Swartz M, et al. Relationship of cognition and psychopathology to functional impairment in schizophrenia. Am J Psychiatry. 2008;165:978-987.

67. Lipkovich IA, Deberdt W, Csernansky JG, et al. Relationships among neurocognition, symptoms and functioning in patients with schizophrenia: a path-analytic approach for associations at baseline and following 24 weeks of antipsychotic drug therapy. BMC Psychiatry. 2009;9:44. 
68. Percudani M. Health care costs of therapyrefractory schizophrenic patients treated with clozapine: a study in a community psychiatric service in Italy. Acta Psychiatr Scand. 1999;99:271280.

69. Mangalore R, Knapp M. Cost of schizophrenia in England. J Ment Health Policy Econ. 2007;10:23-41.

70. Goeree R, Farahati F, Burke N, et al. The economic burden of schizophrenia in Canada in 2004. Curr Med Res Opin. 2005;21:2017-2028.

71. Patel A, Everitt B, Knapp M, et al. Schizophrenia patients with cognitive deficits: factors associated with costs. Schizophr Bull. 2006;32:776-785.

72. Loosbrock DL, Zhao Z, Johnstone BM, Morris LS. Antipsychotic medication use patterns and associated costs of care for individuals with schizophrenia. J Mental Health Policy Econ. 2003;6:67-75.

73. McCombs JS, Nichol MB, Johnstone BM, et al. Antipsychotic drug use patterns and the cost of treating schizophrenia. Psychiatr Serv. 2000;51:525-527.

74. Tarricone R, Gerzeli S, Montanelli R, et al. Direct and indirect costs of schizophrenia in community psychiatric services in Italy. The GISIES study. Interdisciplinary Study Group on the Economic Impact of Schizophrenia. Health Policy. 2000;51:1-18.
75. Dernovsek MZ, Prevolnik R, Rebolj M, Tavcar R. Quality of life and treatment costs in schizophrenic outpatients, treated with depot neuroleptics. Eur Psychiatry. 2001;16:474-482.

76. Heider D, Bernert S, Konig H, et al. Direct medical mental healthcare costs of schizophrenia in France, German and the United Kingdom: findings from the European Schizophrenia Cohort. Eur Psychiatry. 2009;24:216-224.

77. Rofail D, Heelis R, Gournay K. Results of a thematic analysis to explore the experiences of patients with schizophrenia taking antipsychotic medication. Clin Ther. 2009;31 (Pt 1):1488-1496.

78. Knapp M, Razzouk D. Costs of schizophrenia. Psychiatry. 2008;7:491-494.

79. Percudani M, Barbui C, Tansella M. Effect of second-generation antipsychotics on employment and productivity in individuals with schizophrenia: An economic perspective. Pharmacoeconomics. 2004;22:701-718.

80. Rosenheck R, Leslie D, Keefe R, et al. Barriers to employment for people with schizophrenia. Am J Psychiatry. 2006;163:411-417.

81. Wilkinson G, Hesdon B, Wild D, et al. Selfreport quality of life measure for people with schizophrenia: the SQLS. $\mathrm{Br} \mathrm{J}$ Psychiatry. 2000;177:42-46. 